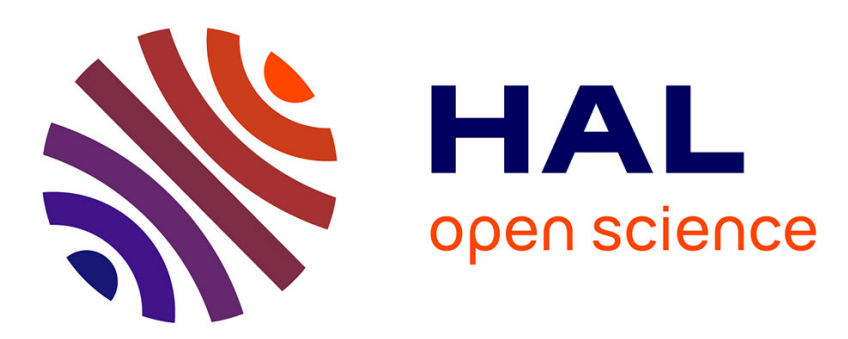

\title{
A real time neural energy management strategy for a hybrid pneumatic engine
}

Guillaume Colin, Gérard Bloch, Yann Chamaillard, Andrej Ivanco

\section{To cite this version:}

Guillaume Colin, Gérard Bloch, Yann Chamaillard, Andrej Ivanco. A real time neural energy management strategy for a hybrid pneumatic engine. IFAC Symposium Advances in Automotive Control, AAC 2010, Jul 2010, Munich, Germany. pp.CDROM. hal-00476666

\section{HAL Id: hal-00476666 https://hal.science/hal-00476666}

Submitted on 26 Apr 2010

HAL is a multi-disciplinary open access archive for the deposit and dissemination of scientific research documents, whether they are published or not. The documents may come from teaching and research institutions in France or abroad, or from public or private research centers.
L'archive ouverte pluridisciplinaire HAL, est destinée au dépôt et à la diffusion de documents scientifiques de niveau recherche, publiés ou non, émanant des établissements d'enseignement et de recherche français ou étrangers, des laboratoires publics ou privés. 


\title{
A real time neural energy management strategy for a hybrid pneumatic engine ${ }^{\star}$
}

\author{
Guillaume Colin* Gérard Bloch** Yann Chamaillard* \\ Andrej Ivanco* \\ * University of Orléans, Institut PRISME, France \\ \{guillaume.colin@univ-orleans.fr\} \\ ** Centre de Recherche en Automatique de Nancy (CRAN UMR 7039), \\ Nancy-Université, CNRS, France \{gerard.bloch@esstin.uhp-nancy.fr\}
}

\begin{abstract}
Various energy management strategies for a hybrid pneumatic engine are reviewed and a real time neural control strategy proposed. This Neural Network strategy learns off line the optimal control given by Dynamic Programming and the resulting control model is applied on line. The different strategies are simulated with a backward vehicle model for various driving cycles and their fuel consumptions compared. The results show that the Neural Network strategy is better than a classical Equivalent Consumption Minimization Strategy (ECMS) and equivalent to a Variable Penalty Coefficient Strategy with Driving Pattern Recognition.
\end{abstract}

Keywords: energy management strategy, fuel saving, hybrid vehicle, hybrid pneumatic engine, optimal control, neural networks, dynamic programming

\section{INTRODUCTION}

Several concepts have been recently proposed to improve the global powertrain efficiency of Internal Combustion Engines (ICE) and consequently decrease their environmental impact. Among these, the hybrid-pneumatic engine differs significantly from the well-known hybrid-electric configuration by the use of compressed air instead of electrical power. In a hybrid-pneumatic engine (Higelin et al.,

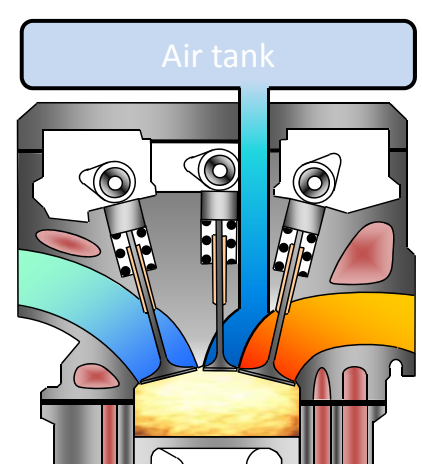

Fig. 1. Pneumatic-hybrid scheme

2002), a traditional ICE is internally hybridized, with a built-in pneumatic motor composed of a compressed air tank linked to the combustion chamber by a supplementary pipe and an additional charging valve (see Figure 1). This allows the hybrid engine to store kinetic energy of the vehicle in the air tank without additional compressor and to restore it to produce torque. The hybrid-pneumatic engine could be considered as a parallel hybrid configuration, where both the ICE and pneumatic motor are coupled on

\footnotetext{
^ This work was partially supported by ANR project ArHyCo, Programme "Systèmes Embarqués et Grandes Infrastructures" ARPEGE, contract number ANR-2008 SEGI 004 01-30011459.
}

a single crankshaft and could work separately or together in a supercharging mode.

This concept has three main advantages, leading to significant fuel saving: possibility to recuperate kinetic energy; no additional clutch, reducer or continuously variable transmission; reduction in the turbo lag during acceleration and possibility of strong engine downsizing, as studied in (Doenitz et al., 2009).

To implement the proposed concept it is necessary to optimize not only the pneumatic motor, but also the energy management strategy. Section 2 describes the backward vehicle model used to simulate the control strategies. These ones are summarized in Section 3: the reference given off line by Dynamic Programming, the basic Causal Strategy, the different Penalty Coefficient strategies, including Driving Pattern Recognition techniques for adapting the penalty coefficient, and the proposed Neural Network strategy, which learns off line the reference optimal control and applies it on line. Comparisons for different driving cycles are given in section 4.

\section{VEHICLE MODEL}

To simulate and compare the energy management strategies on the vehicle speed profiles of some driving cycles, backward and forward models of vehicle can be used. In the discrete time backward model used here, the desired vehicle speed is interpreted as a torque demand taking into account the models of the vehicle and power transmission. This Hybrid Pneumatic Engine model is presented in Figure 2, where the blocks refer to the equations detailed below.

Firstly, from the cycle desired speed $v_{d}(\mathrm{~m} / \mathrm{s})$, the acceleration $\Gamma\left(\mathrm{m} / \mathrm{s}^{2}\right)$ is estimated simply by:

$$
\Gamma(k)=\frac{v_{d}(k)-v_{d}(k-1)}{\Delta t}
$$




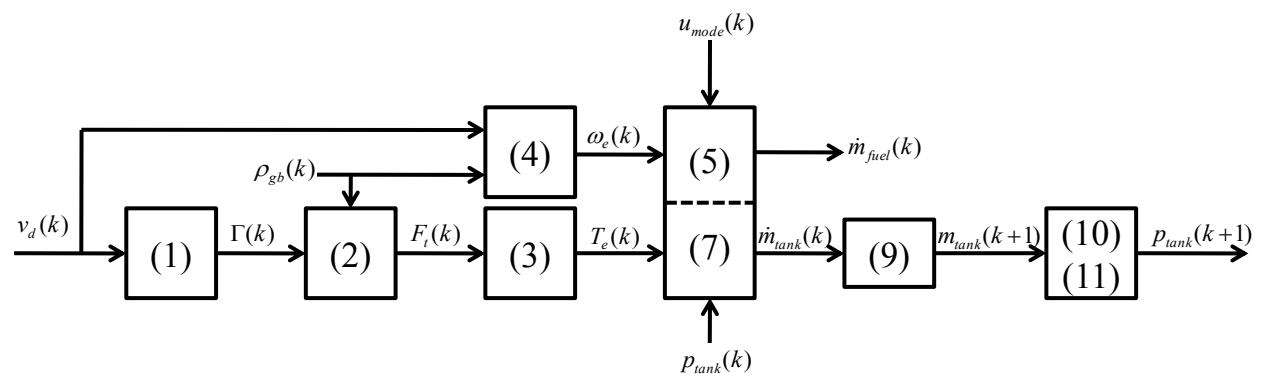

Fig. 2. Global model of the Hybrid Pneumatic Engine

where $\Delta t(\mathrm{~s})$ is the sampling period. Next, considering the forces $(\mathrm{N})$ acting on the vehicle (aerodynamics $F_{a}$, rolling resistance $F_{r}$, wheel inertia $\left.F_{w}\right)$, the traction force $F_{t}$ is deduced from:

$$
m \Gamma(k)=-F_{a}(k)-F_{r}(k)-F_{w}(k)+F_{t}(k)
$$

where $m(\mathrm{~kg})$ is the vehicle mass. Then the requested engine torque $T_{e}(\mathrm{Nm})$ can be obtained by:

$$
T_{e}(k)=\frac{F_{t}(k) \cdot r_{w}}{\rho_{g b}(k)} \cdot \eta_{g b}^{-\operatorname{sign}\left(F_{t}\right)}+T_{a u x}(k)+T_{\text {friction }}(k)
$$

where the transmission chain characteristics (final reduction and gear-box ratio $\rho_{g b}$ ), the wheel radius under load $r_{w}(\mathrm{~m})$, the gear box efficiency $\eta_{g b}$, the auxiliary $T_{a u x}$ and friction $T_{\text {friction }}$ torques $(\mathrm{Nm})$ are taken into account. Next, the engine speed $\omega_{e}(\mathrm{rpm})$ is deduced:

$$
\omega_{e}(k)=\frac{v_{d}(k) \rho_{g b}(k) 30}{r_{w} \pi}
$$

In order to compare the fuel consumptions, the gearbox switching strategy of the conventional engine mode is kept for all the energy management strategies.

The control of the produced torque is then divided in two levels. A supervisory level chooses the propulsion mode $u_{\text {mode }}$ in order to minimize the fuel consumption. A lowlevel controller manipulates the engine actuators in order to produce the requested torque. In all, four driving modes are considered:

- two propulsive modes $u_{\text {mode }}$ : pneumatic $\mu_{p}$ and conventional $\mu_{c}$,

- one recuperative: pneumatic pump,

- and one alternative: engine stop.

These four modes are characterized in Table 1 versus the mass flowrates of the air trapped in the tank $\dot{m}_{\text {tank }}$ and consumed fuel $\dot{m}_{f u e l}$ and detailed further.

\begin{tabular}{|l||c|c|c|c|}
\hline Mode & Pneumatic $\mu_{p}$ & Convent. $\mu_{c}$ & Pump & Stop \\
\hline$\dot{m}_{\text {tank }}$ & $<0$ & $=0$ & $>0$ & $=0$ \\
\hline$\dot{m}_{\text {fuel }}$ & $=0$ & $>0$ & $=0$ & $=0$ \\
\hline
\end{tabular}

Table 1. Possible driving modes

Conventional propulsive mode. This mode $\mu_{c}$ involves a classical four-stroke combustion cycle, where the effective work is adjusted by acting on the air mass flow through the throttle. A representative quasi-static model of the engine consumption $\dot{m}_{\text {fuel }}$ (g/cycle) is derived from test bench measurements (see Figure 3):

$$
\dot{m}_{f u e l}(k)=g\left(T_{e}(k), \omega_{e}(k)\right)
$$

Note that the engine torque $T_{e}$ is bounded and the conventional mode cannot be used below the idle speed $\omega_{\text {idle: }}$

$$
\left\{\begin{array}{l}
T_{e \_m i n}\left(\omega_{e}(k)\right) \leq T_{e}(k) \leq T_{e_{-} \max }\left(\omega_{e}(k)\right) \\
\omega_{e}(k) \geq \omega_{\text {idle }}
\end{array}\right.
$$

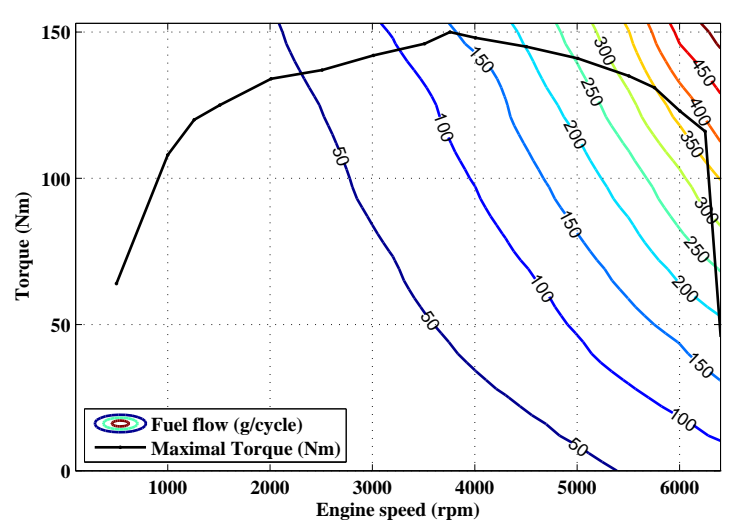

Fig. 3. Conventional propulsive mode: fuel flowrate $\dot{m}_{f u e l}$ versus engine speed $\omega_{e}$ and requested torque $T_{e}$

Pneumatic propulsive mode. This mode $\mu_{p}$, where the intake phase is suspended, can produce torque from the compressed air, even from zero engine speed. To reduce the computation times, all the thermodynamic cycles have been recalculated in the form of a cartography shown in Figure 4, giving the consumed air mass flowrate $\dot{m}_{\text {tank }}(k)$ (g/cycle):

$$
\dot{m}_{\text {tank }}(k)=h\left(T_{e}(k), \omega_{e}(k)\right)
$$

where the requested engine torque $T_{e}$ is also bounded:

$$
T_{e_{-} \min }\left(p_{\text {tank }}(k)\right) \leq T_{e}(k) \leq T_{e_{-} \max }\left(p_{\text {tank }}(k)\right)
$$

Indeed, the pneumatic motor mode cannot be used (e.g. for stop and start functionality) below a certain value of air-tank pressure $p_{\text {tank_min }}$, where the demanded torque could not be delivered. The maximal pressure depends on the compression ratio of the engine and when reached, the pumping mode quickly loses its effectiveness.

Then, the tank air mass $m_{\text {tank }}(\mathrm{kg})$ is computed by integrating the tank air flowrate $\dot{m}_{\text {tank }}$ : 


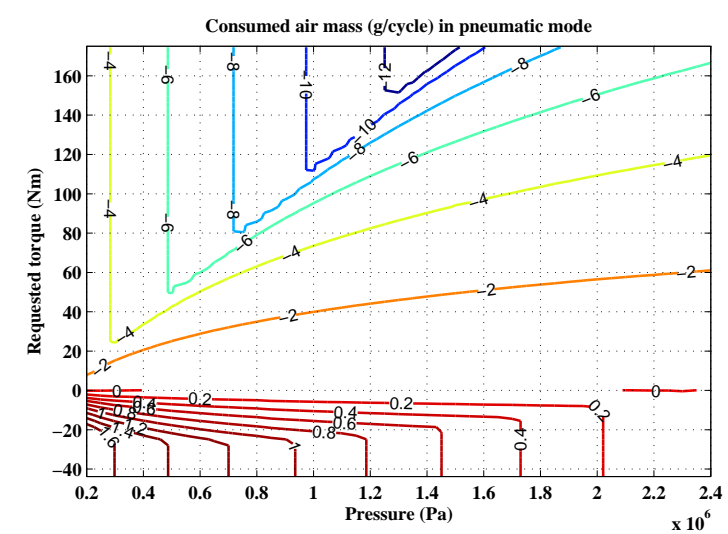

Fig. 4. Pneumatic propulsive mode: consumed air massflow $\dot{m}_{\text {tank }}$ versus pressure $p_{\text {tank }}$ and requested torque $T_{e}$

$$
m_{\text {tank }}(k+1)=m_{\text {tank }}(k)+\dot{m}_{\text {tank }}(k) \frac{\omega_{e}(k) \Delta t}{12010^{3}}
$$

Finally, the tank pressure $p_{\text {tank }}(\mathrm{Pa})$ is deduced from:

$$
\begin{gathered}
\theta_{\text {tank }}(k+1)=\theta_{\text {amb }}\left(\frac{p_{\text {tank }}(k+1)}{p_{\text {amb }}}\right)^{\frac{\gamma-1}{\gamma}} \\
p_{\text {tank }}(k+1)=\frac{r m_{\text {tank }}(k+1) \theta_{\text {tank }}(k+1)}{V_{\text {tank }}}
\end{gathered}
$$

where $\theta_{\text {tank }}(\mathrm{K})$ is the tank temperature, $\theta_{a m b}(\mathrm{~K})$ and $p_{a m b}(\mathrm{~Pa})$ the ambient temperature and pressure, $\gamma$ the specific heat ratio, $V_{\text {tank }}\left(\mathrm{m}^{3}\right)$ the air tank volume and $r$ $(\mathrm{J} / \mathrm{kg} / \mathrm{K})$ the perfect gas constant.

Recuperative pneumatic mode. This pumping mode is used to transform the kinetic energy from the vehicle to potential energy in the form of compressed air stored in the air-tank. Basically it is the opposite of the pneumatic propulsive mode (capturing air to the air-tank instead of releasing it). More details about the thermodynamic cycles in a pneumatic-hybrid engine could be found in (Brejaud et al., 2009).

\section{ENERGY MANAGEMENT STRATEGIES}

\subsection{Introduction}

An energy management strategy could be considered as a decision system where the main objective is to minimize the overall fuel consumption (Guzzella and Sciarretta, 2005). The energy management strategies can be divided into two main groups.

Offline. Knowing the cycle profile from the start to the end yields to the best possible energy savings on this cycle. This knowledge is obviously not available in real time, but it is used by Dynamic Programming to obtain the global optimal solution in order to benchmark the online energy management strategies.

Online. Information about the current status of the powertrain, the past driven cycle or from on-board sensors is only available. Causal, Penalty Coefficient and Neural Network are online strategies.

A basic decision system, shown in Figure 5, is used by all the energy management strategies in the case of negative torque demand ( $T_{e} \leq 0$, decceleration). On one hand, if $\omega_{e}>\omega_{\text {idle }}$, the chosen mode is the recuperative pneumatic pump (no dissipative vehicle breaking) possibly with classical breaking if the deceleration torque is greater than the maximum of regenerative breaking $T_{\text {pump_max }}$. On the other hand, when $\omega_{e} \leq \omega_{i d l e}$, if $p_{\text {tank }}>p_{\text {tank_min }}$ (minimal tank pressure to restart the engine), the engine is stopped otherwise conventional idling is engaged.

Finally, if the demanded torque $T_{e}$ is positive, one has only to select the conventional $\mu_{c}$ or pneumatic $\mu_{p}$ propulsive mode, so that $u_{\text {mode }} \in\left\{\mu_{c}, \mu_{p}\right\}$.

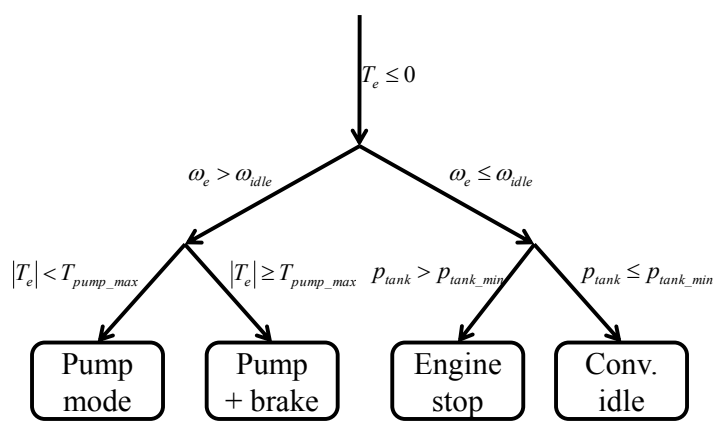

Fig. 5. Decision tree for all strategies management

\subsection{Driving cycles}

Different driving cycles are used to evaluate the performance of the energy management strategies. The first one is the well known New European Driving Cycle (NEDC) which is a governmental reference for comparative evaluation of fuel consumptions. It is refered here as cycle 1 . The other driving cycles used here are shown in Figure 6. The ARTEMIS cycles are selected from (André, 2004) to give a more realistic overview of the driving conditions (Trafficjam, Urban, Road, and Highway, called here cycles 2, 3, $4,5)$. Next, a reference cycle, called cycle 10, combines these ARTEMIS cycles. Finally, three other driving cycles (cycles 11, 12, 13), proposed in (Ivanco et al., 2009a), are used to validate extrapolation behavior.

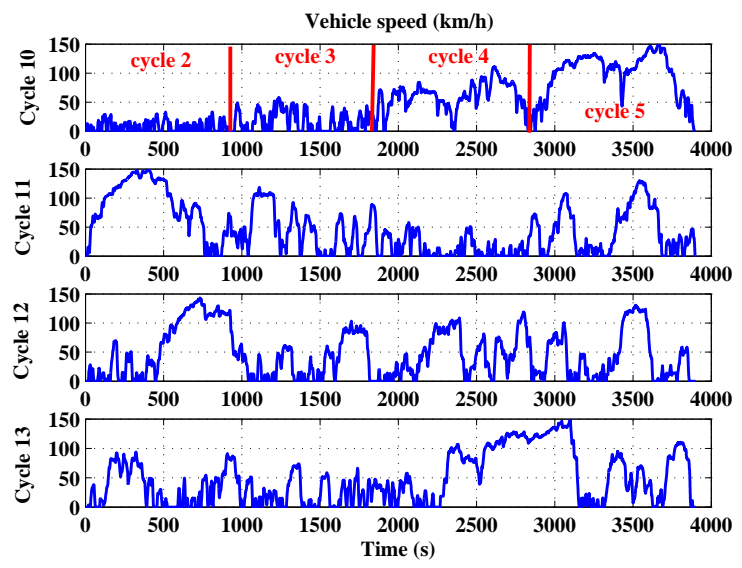

Fig. 6. Generated driving patterns

\subsection{Dynamic Programming (DP)}

Dynamic Programming (DP) is an off-line reference strategy. Knowing the whole speed profile and having a precise 
model of the system allow to calculate all the possible states during the driving cycle and find the sequence of the propulsion modes with the smallest overall consumption. Let us consider, on $N$ time steps, the non linear discrete time vehicle model described in the previous section 2 :

$$
x_{k+1}=f\left(x_{k}, u_{k}, \mathbf{w}_{k}\right), k=0,1, \ldots, N-1
$$

where the state $x_{k}$ is the tank pressure $p_{\text {tank }}(k)$, the control $u_{k}$ is the propulsive mode $u_{\text {mode }}(k) \in\left\{\mu_{c}, \mu_{p}\right\}$ and where $\mathbf{w}_{k}$ includes the other inputs of the model (e.g. gear number $\left.\rho_{g b}\right)$. Let the cost of using a control sequence $\pi=\left\{u_{0}, \ldots, u_{N-1}\right\}$ with the initial state $x_{0}=x(0)$ be:

$$
J_{\pi}\left(x_{0}\right)=\sum_{k=0}^{N-1} g_{k}\left(x_{k}, u_{k}, \mathbf{w}_{k}\right)+h_{N}\left(x_{N}\right)
$$

The cost function $g_{k}$ is the fuel consumption of the combustion engine (5). The final cost $h_{N}\left(x_{N}\right)$ is chosen here zero for equal initial and final pressures, infinite otherwise, thus forcing a charge sustaining solution. Minimizing the cost over the set $\Pi$ of all admissible control sequences gives the optimal solution:

$$
\pi^{*}=\arg \min _{\pi \in \Pi} J_{\pi}\left(x_{0}\right)
$$

Bellman's principle of optimality states that an optimal input trajectory for a discrete decision problem from the initial state to the final state is also optimal from the current state to the final state. Based on this, Dynamic Programming proceeds backward in time from the final state to the initial state using:

$$
J_{i}\left(x_{i}\right)=\min _{u_{i}} g_{i}\left(x_{i}, u_{i}, \mathbf{w}_{i}\right)+J_{i+1}\left(f\left(x_{i}, u_{i}, \mathbf{w}_{i}\right)\right)
$$

An equivalent Dynamic Programming algorithm which proceeds forward in time is used here (Bertsekas, 2005).

\subsection{Causal strategy}

The Causal Strategy (CS) implements a rule-based control with the aim of operating the engine in a high-efficiency region. Though strongly application-dependant (Sciarretta and Guzzella, 2003), it can give results close to the optimal strategy. For the hybrid pneumatic engine, in addition to the common rules described above, the decision is made from the demanded torque $T_{e}$, engine speed $\omega_{e}$ and tank pressure $p_{\text {tank }}$ as shown on figure 7 , where $p_{\text {tank_des }}$ represents the desired air tank pressure.

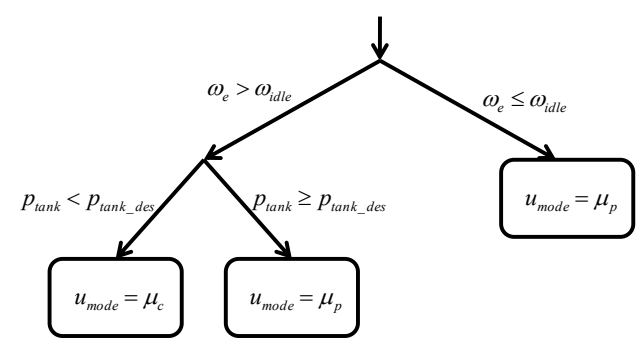

Fig. 7. Decision tree for the Causal Strategy

\subsection{Penalty Coefficient strategies}

This type of strategies is often refered to as Equivalent Consumption Minimization Strategy (ECMS) (Paganelli et al., 2002; Guzzella and Sciarretta, 2005). It minimises the instantaneous consumption, but includes a chargesustaining penalty bounding the air tank pressure. The energies are compared in $\mathrm{J} /$ cycle, with, for the pneumatic mode:

$$
E_{\text {tank }}=\dot{m}_{\text {tank }} C_{p} \theta_{\text {tank }}
$$

with $\dot{m}_{\text {tank }}$ the compressed air mass flowrate, $C_{p}$ the specific heat capacity and $\theta_{\text {tank }}$ the tank temperature, and, for the conventional mode:

$$
E_{f u e l}=\dot{m}_{f u e l} L C V
$$

with $\dot{m}_{f u e l}$ the fuel mass flowrate and $L C V$ is the fuel Lower Calorific Value. The chosen mode is the one with the penalized lowest equivalent energy:

$$
u_{\text {mode }}= \begin{cases}\mu_{c} & \text { if } E_{\text {tank }} \lambda>E_{\text {fuel }} \\ \mu_{p} & \text { else }\end{cases}
$$

where $\lambda$ is the penalty coefficient. As in (Ivanco et al., 2009b), one can choose a Constant Penalty Coefficient (CPC) or a Variable Penalty Coefficient (VPC):

$$
\lambda(k)=\lambda_{0}-\left(\frac{2 p_{\text {tank }}(k)\left(p_{\max }+p_{\min }\right)}{p_{\max }-p_{\min }}\right)^{n}
$$

illustrated in Figure 8, which avoids saturating the tank pressure. Indeed, above a certain tank pressure, no energy can be recuperated, and, under a tank pressure value, the stop mode cannot be used. Both $\lambda$ in CPC and $\lambda_{0}$ and $n$ in VPC have to be determined off line to obtain the best fuel saving for given driving cycles.

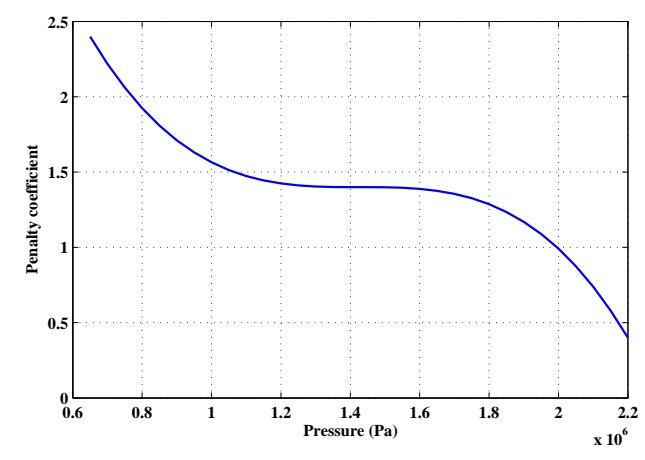

Fig. 8. Variable Penalty Coefficient versus tank pressure

The penalty coefficent can also be adapted on line by using a Driving Pattern Recognition (DPR) technique (Jeon et al., 2002; Ivanco et al., 2009b). Several driving conditions can be listed, for example from the ARTEMIS cycles: Traffic Jam, Urban, Road and Highway. These driving patterns can be characterized by the empirical distribution of related variables, like torque demand as shown in Figure 9. Histogram-based pattern recognition is widely used for image classification or object tracking. Here, the current driving condition is recognized by comparing histograms 


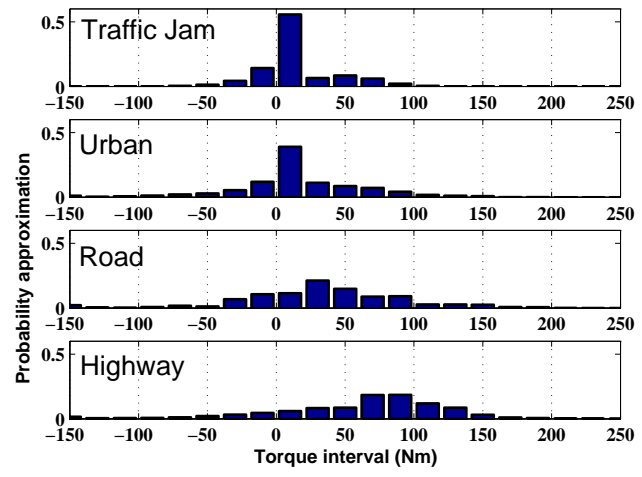

Fig. 9. Histograms of torque demand for the reference patterns

of a moving window with the reference ones, for example by correlation. Then the current penalty coefficient can be chosen as the one previously computed during the off-line optimization for the recognized driving condition, leading to the Constant Penalty Coefficient with Driving Pattern Recognition (CPC-DPR) and Variable Penalty Coefficient with Driving Pattern Recognition (VPC-DPR) strategies.

\subsection{Neural Network energy management strategy}

The Neural Network (NN) strategy, proposed here, consists in learning, from the current avalaible variables, the optimal control solution generated by Dynamic Programming and applying the learned control in real time.

As a parsimonious and flexible universal approximator, a perceptron with one hidden layer and a linear output unit is used. For a scalar function, its form is given by:

$$
f_{n n}(\boldsymbol{\varphi})=\sum_{k=1}^{n} w_{k}^{2} g\left(\sum_{j=1}^{p} w_{k j}^{1} \varphi_{j}+b_{k}^{1}\right)+b^{2},
$$

where $\boldsymbol{\varphi}=\left[\varphi_{1} \ldots \varphi_{p}\right]^{T}$ is the regression vector, the $w_{k j}^{1}, b_{k}^{1}$ are the parameters of the $n$ hidden neurons, the activation function $g$ is the hyperbolic tangent, and the $w_{k}^{2}, b^{2}$ are the parameters of the output neuron.

The useful regressors $\varphi_{j}$ are selected fairly elementary by stepwise regression for a linear model: tank pressure $p_{\text {tank }}(\mathrm{Pa})$, traction force $F_{t}(\mathrm{~N})$, vehicle speed $v_{d}(\mathrm{~m} / \mathrm{s})$ and acceleration $\gamma\left(\mathrm{m} / \mathrm{s}^{2}\right)$, gearshift $\rho_{g b}$, engine speed $\omega_{e}$ $(\mathrm{rpm})$, requested torque without friction and auxiliary $T_{e}-T_{\text {friction }}-T_{\text {aux }}(\mathrm{Nm})$, friction torque $T_{\text {friction }}(\mathrm{Nm})$, auxiliary torque $T_{\text {aux }}(\mathrm{Nm})$.

The outputs to be predicted, i.e. the optimal sequence given by DP, are coded by 1 for the conventional mode $\mu_{c}$ and -1 for the pneumatic mode $\mu_{p}$.

Training was performed by minimizing the mean squared error with the Levenberg-Marquardt algorithm. The chosen number of hidden neurons corresponds to the minimum of the fuel consumption.

Finally, the control to be used on line is given by:

$$
u_{\text {mode }}=\operatorname{sign}\left(f_{n n}(\boldsymbol{\varphi})\right)
$$

\section{RESULTS}

In this section, the strategies are compared on the different cycles, with a backward model of a middle class vehicle (vehicle mass $m$ of $1500 \mathrm{~kg}, 5$ speed gear box and 1.61 gasoline engine) and a sampling period $\Delta t=0.5 \mathrm{~s}$ :

- DP: Dynamic Programming (optimal) strategy

- VPC-DPR: Variable Penalty Coefficient with Driving Pattern Recognition strategy (for the four ARTEMIS cycles: $\lambda_{0}=(1.35,1.55,1.35,0.4), \mathbf{n}=(3,15,15,1)$; driving condition recognition from the greatest correlation between requested torque histograms and, if ambiguity, by comparing the current vehicle speed $v_{d}(k)$ with the mean speeds $\bar{v}_{i}$ of the cycles)

- VPC: Variable Penalty Coefficient strategy $\left(\lambda_{0}=1.4\right.$, $n=3$ (see Figure 8) obtained from the minimal sum of the fuel consumptions of the four ARTEMIS cycles)

- NN: Neural Network strategy (structure (10 neurons) and parameters of the neural model obtained from cycle 10, combination of the four ARTEMIS cycles)

- CPC-DPR: Constant Penalty Coefficient with Driving Pattern Recognition strategy (same driving condition recognition as in VPC-DPR, $\lambda_{0}=(2.05,1.45,1.35,1.25)$ obtained as in VPC $)$.

- CPC: Constant Penalty Coefficient strategy $(\lambda=1.6$, obtained as in VPC)

- CS: Causal Strategy ( $p_{\text {tank_des }}=10$ bar $)$

- Conventional mode (no hybridization)

The initial and final tank pressures are fixed equal (10 bar) for the DP strategy, except for the NEDC cycle, where the final pressure exceeds 10 bar, because the braking energy is always recuperated (see Figure 5) and the NEDC ends with braking (see Figure 10). This initial tank pressure is kept for the real time strategies to compare the resulting consumptions. The differences in the final pressure between all strategies are considered as negligible.

Tables 2 and 3 show the Fuel Consumption (FC in $\mathrm{L} / 100 \mathrm{~km}$ ) and Final Pressure (FP in bar). They show that the Neural Network strategy yields to results similar to the VPC strategies and better than the Causal and CPC strategies. Figure 10 shows the tank pressure for the optimal DP strategy and the neural strategy on the European Driving Cycle (NEDC). It can be seen that the dynamics are often similar because the chosen modes are often the same as shown on figure 11.

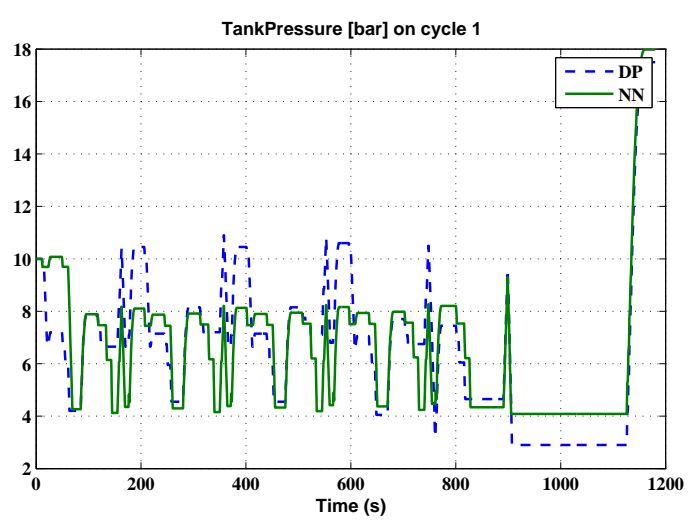

Fig. 10. Tank Pressure (bar) for the Neural Network and Dynamic Programming strategies on the NEDC cycle 


\begin{tabular}{|c|c|c|c|c|c|c|c|c|c|c|c|}
\hline Strategy & $\begin{array}{c}\text { Cycle } \\
\text { FC }\end{array}$ & $\begin{array}{c}2 \\
\text { FP }\end{array}$ & $\begin{array}{c}\text { Cycle } \\
\text { FC }\end{array}$ & $\begin{array}{c}3 \\
\text { FP }\end{array}$ & $\begin{array}{c}\text { Cycle } \\
\text { FC }\end{array}$ & $\begin{array}{c}4 \\
\mathrm{FP}\end{array}$ & $\begin{array}{c}\text { Cycle } \\
\text { FC }\end{array}$ & $\begin{array}{c}5 \\
\text { FP }\end{array}$ & $\begin{array}{c}\text { Cycle } \\
\text { FC }\end{array}$ & $\begin{array}{l}10 \\
\text { FP }\end{array}$ & $\begin{array}{c}\text { Average } \\
\text { FC }\end{array}$ \\
\hline$\overline{\mathrm{DP}}$ & 8.51 & 10.00 & 7.10 & 10.00 & 5.71 & 10.00 & 8.94 & 10.00 & 7.47 & 10.00 & 7.55 \\
\hline VPC-DPR & 8.65 & 9.73 & 7.27 & 9.37 & 5.76 & 10.96 & 8.96 & 10.97 & 7.52 & 11.82 & 7.63 \\
\hline VPC & 8.67 & 10.01 & 7.29 & 10.39 & 5.78 & 12.86 & 8.97 & 12.21 & 7.54 & 13.08 & 7.65 \\
\hline NN & 8.56 & 10.4 & 7.28 & 11.05 & 5.81 & 15.2 & 8.96 & 15.15 & 7.54 & 15.05 & 7.63 \\
\hline CPC-DPR & 9.07 & 13.52 & 7.30 & 8.47 & 5.78 & 10.36 & 8.94 & 10.97 & 7.53 & 11.72 & 7.72 \\
\hline $\mathrm{CPC}$ & 10.33 & 8.97 & 7.25 & 10.63 & 5.81 & 14.96 & 8.96 & 15.24 & 7.62 & 16.11 & 7.99 \\
\hline Causal & 8.91 & 9.80 & 7.53 & 11.75 & 5.86 & 11.42 & 9.02 & 11.18 & 7.61 & 11.59 & 7.79 \\
\hline Conventional & 14.51 & - & 10.41 & - & 6.24 & - & 9.10 & - & 8.31 & - & 9.71 \\
\hline
\end{tabular}

Table 2. Strategy comparison for the ARTEMIS cycles (2 to 5 ) and the combined cycle (10)

\begin{tabular}{|c||cc|cc|cc|cc|c|}
\hline & Cycle & 1 & Cycle & 11 & Cycle & 12 & Cycle & 13 & Average \\
Strategy & FC & FP & FC & FP & FC & FP & FC & FP & FC \\
\hline DP & 6.14 & 17.50 & 7.54 & 10.00 & 7.24 & 10.00 & 7.29 & 10.00 & 7.05 \\
VPC-DPR & $\mathbf{6 . 2 0}$ & 19.26 & 7.62 & 10.11 & $\mathbf{7 . 3 0}$ & 12.86 & $\mathbf{7 . 3 4}$ & 10.42 & $\mathbf{7 . 1 2}$ \\
VPC & 6.23 & 19.83 & $\mathbf{7 . 6 1}$ & 10.84 & 7.32 & 13.91 & 7.36 & 12.17 & 7.13 \\
NN & $\mathbf{6 . 2 0}$ & 17.99 & 7.67 & 8.00 & 7.35 & 11.55 & 7.41 & 12.37 & 7.16 \\
CPC-DPR & 6.28 & 18.58 & 7.72 & 6.50 & 7.35 & 11.30 & 7.40 & 9.66 & 7.19 \\
CPC & 6.35 & 19.68 & 7.72 & 8.68 & 7.33 & 12.66 & 7.39 & 12.11 & 7.20 \\
Causal & 6.3 & 18.94 & 7.70 & 12.42 & 7.40 & 14.03 & 7.44 & 14.03 & 7.21 \\
Conventional & 7.31 & - & 8.40 & - & 8.14 & - & 8.12 & - & 7.99 \\
\hline
\end{tabular}

Table 3. Strategy comparison for the test cycles 1 (NEDC), 11, 12 and 13
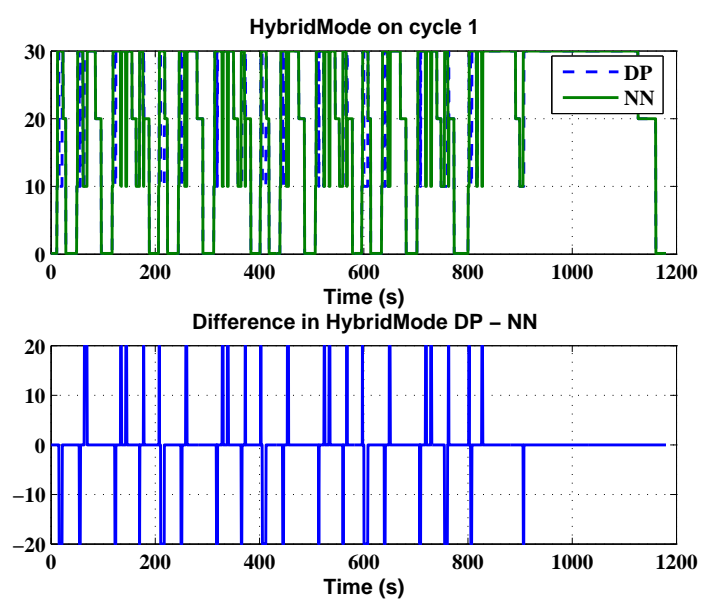

Fig. 11. Chosen mode for the Neural Network and Dynamic Programming strategies on the NEDC cycle

\section{CONCLUSION}

We reviewed the energy management strategies for a hybrid pneumatic engine and proposed a real time neural control strategy. This Neural Network strategy learns off line the optimal control given by Dynamic Programming. Note that the presented learning is quite basic and can be enhanced. The different strategies are simulated for various driving cycles and their fuel consumptions compared. The results show that the Neural Network strategy is better than a classical Equivalent Consumption Minimization Strategy (ECMS) and equivalent to a Variable Penalty Coefficient Strategy with Driving Pattern Recognition. Although a precise evaluation of the computational burden and time has not been done, all the presented strategies, including the proposed one, can be used in real time.

\section{REFERENCES}

André, M. (2004). The ARTEMIS European driving cycles for measuring car pollutant emissions. Sci. Total
Environ., 334-335, 73-84.

Bertsekas, D.P. (2005). Dynamic Programming and optimal control. Athena Scientific.

Brejaud, P., Charlet, A., Chamaillard, Y., Ivanco, A., and Higelin, P. (2009). Pneumatic-combustion hybrid engine: a study of the effect of the valvetrain sophistication on pneumatic modes. Oil Gas Sci. Technol., in Press.

Doenitz, C., Vasile, I., Onder, C.H., and Guzzella, L. (2009). Realizing a concept for high efficiency and excellent driveability: The downsized and supercharged hybrid pneumatic engine. SAE Paper n 2009-01-1326.

Guzzella, L. and Sciarretta, A. (2005). Vehicle propulsion systems: Introduction to modeling and optimization. Springer.

Higelin, P., Charlet, A., and Chamaillard, Y. (2002). Thermodynamic simulation of a hybrid pneumaticcombustion engine concept. Int. J. Applied Thermodynamics, 5(1), 1-11.

Ivanco, A., Chamaillard, Y., Charlet, A., and Higelin, P. (2009a). Energy management strategies for hybridpneumatic engine studied on a Markov chain type generated cycles. SAE Paper $n^{\circ}$ 2009-01-0145.

Ivanco, A., Chamaillard, Y., Charlet, A., and Higelin, P. (2009b). Energy management strategies for pneumatichybrid engine based on sliding window pattern recognition. Oil Gas Sci. Technol., in Press.

Jeon, S., Jo, S., Park, Y., and Lee, J. (2002). Multimode driving control of a parallel hybrid electric vehicle using driving pattern recognition. J. Dyn. Syst. Meas. Control, 124(1), 141-149.

Paganelli, G., Delprat, S., Guerra, T., Rimaux, J., and Santin, J.J. (2002). Equivalent consumption minimization strategy for parallel hybrid powertrains. In Proc. IEEE 55th Vehicular Technology Conference, volume 4, 2076-2081.

Sciarretta, A. and Guzzella, L. (2003). Rule-based and optimal control strategies for energy management in parallel hybrid vehicles. In Proc. 6th International Conference on Engines for Automobile. Capri, Italy. 